\title{
Indolent mucoid carcinoma of stomach
}

\author{
W. L. BRANDER ${ }^{1}$, P. R. G. NEEDHAM, AND A. D. MORGAN \\ From the Department of Histopathology, Westminster Medical School, London
}

SYNOPSIS In a review of 574 cases of gastric carcinoma, $50(8.7 \%)$ proved to be mucoid using defined microscopic criteria. Three histological types were recognized: pure signet-ring cell carcinoma (three cases); tumour of mixed pattern (41 cases); and an easily recognized, well differentiated type (six cases). This last group pursued an indolent course and had a mean survival time of nine years compared with mean survival times in the other two groups of five and 18 months respectively.

Carcinoma of the stomach arises from mucussecreting cells of normal gastric mucosa or from areas of intestinal metaplasia (Morson and Dawson, 1972). Many tumours secrete mucus, which may be intracellular (the so-called 'signet-ring' appearance) or extracellular in which the tumour cells are suspended in abundant pools of mucus. Such growths are often bulky (see fig 1) and may present a semitranslucent, glistening appearance when cut across, which has been variously termed mucoid, colloid, mucinous, or gelatinous, and indiscriminate usage by different authors has led to some confusion. Morson and Dawson (1972) use the term 'well differentiated colloid carcinoma' to denote that type of growth with predominantly extracellular mucin, and 'poorly differentiated' for the signet-ring variety. Fisher and Hoerr (1954) apply 'mucinous' to the former type and 'colloid' to the latter. Stout (1953) regards the terms as synonymous, pointing out that no one has defined how mucinous a tumour must be to justify its inclusion in a special category; what is more important, he sees no virtue in such a subdivision. In the series of cases reviewed here we define our histological criteria for the term 'mucoid' and present evidence that a small but distinct group of highly differentiated mucoid carcinomas of the stomach pursue an indolent course and have a prognosis considerably better than the average gastric cancer.

\section{Histological Classification of Mucoid Carcinoma}

The histological sections of 574 cases of carcinoma of the stomach, either biopsied (17 cases) or resected

'Present address: Department of Pathology, Guy's Hospital Medical School, London SE1 9RT.

Received for publication 24 April 1974.
(557 cases) at the Westminster and Gordon Hospitals between 1939 and 1970 were reviewed and in the first instance separated into mucoid and non-mucoid groups.

The criterion for inclusion in the mucoid group was that $50 \%$ or more of the bulk of the tumour represented in the sections was epithelial mucus, either intracellular or extracellular. This arbitrary criterion was chosen because it was felt that, while some tumours which might be called 'mucoid' would be excluded, all those which conformed to this standard would be worthy of the title 'mucoid' whatever criteria were adopted. Three categories were recognized:

1 Pure signet ring type, in which the mucus is wholly intracellular displacing the nucleus to one side of the cell (fig 2).

2 A pure 'well differentiated' mucoid carcinoma in which the whole of the primary and its metastases consist of lakes of extracellular mucus in which the tumour cells float singly or in groups (fig 3). Individual cells may be bloated with mucus in the general form of a signet-ring cell but they tend to be larger than those of (1) and often appear degenerate, with ill defined cell and nuclear membranes and pyknotic nuclei (fig 4). Epithelial structures may be formed consisting of tubules or ribbons of very well differentiated cells (fig 5), each structure or group of structures separated from other tumour cells by the extracellular mucus. The groups of tubular formations are never large. The advancing edge of the tumour is rounded or 'pushing' as described by Monafo, Krause, and Medina (1962) and consists of mucus often containing very few tumour cells (fig 6).

3 A mixed pattern which may include areas like (1) or (2) mingled with other histological patterns either anaplastic or variably differentiated glandular 


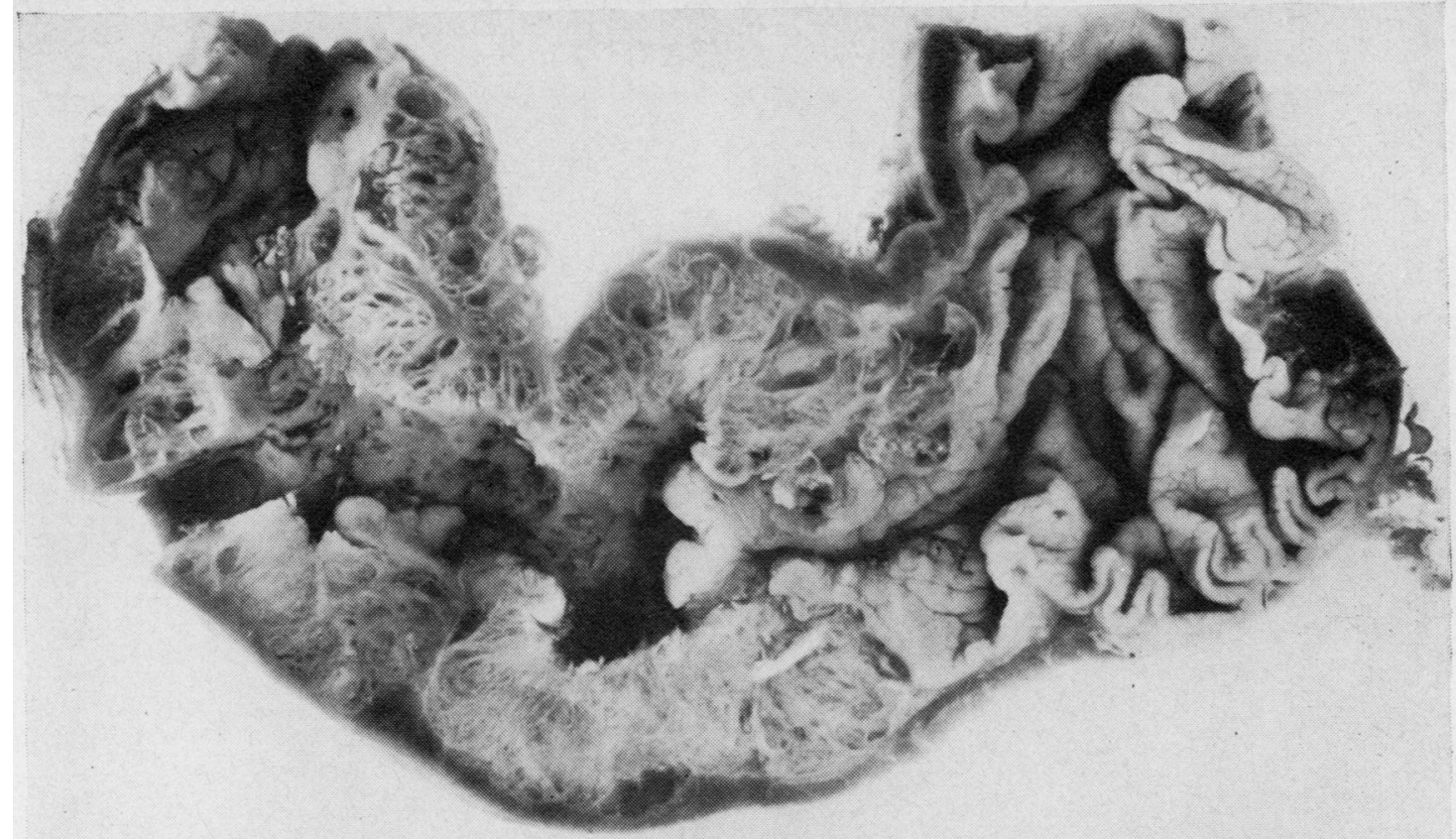

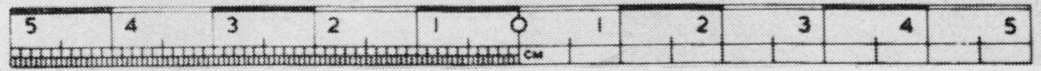

Fig 1
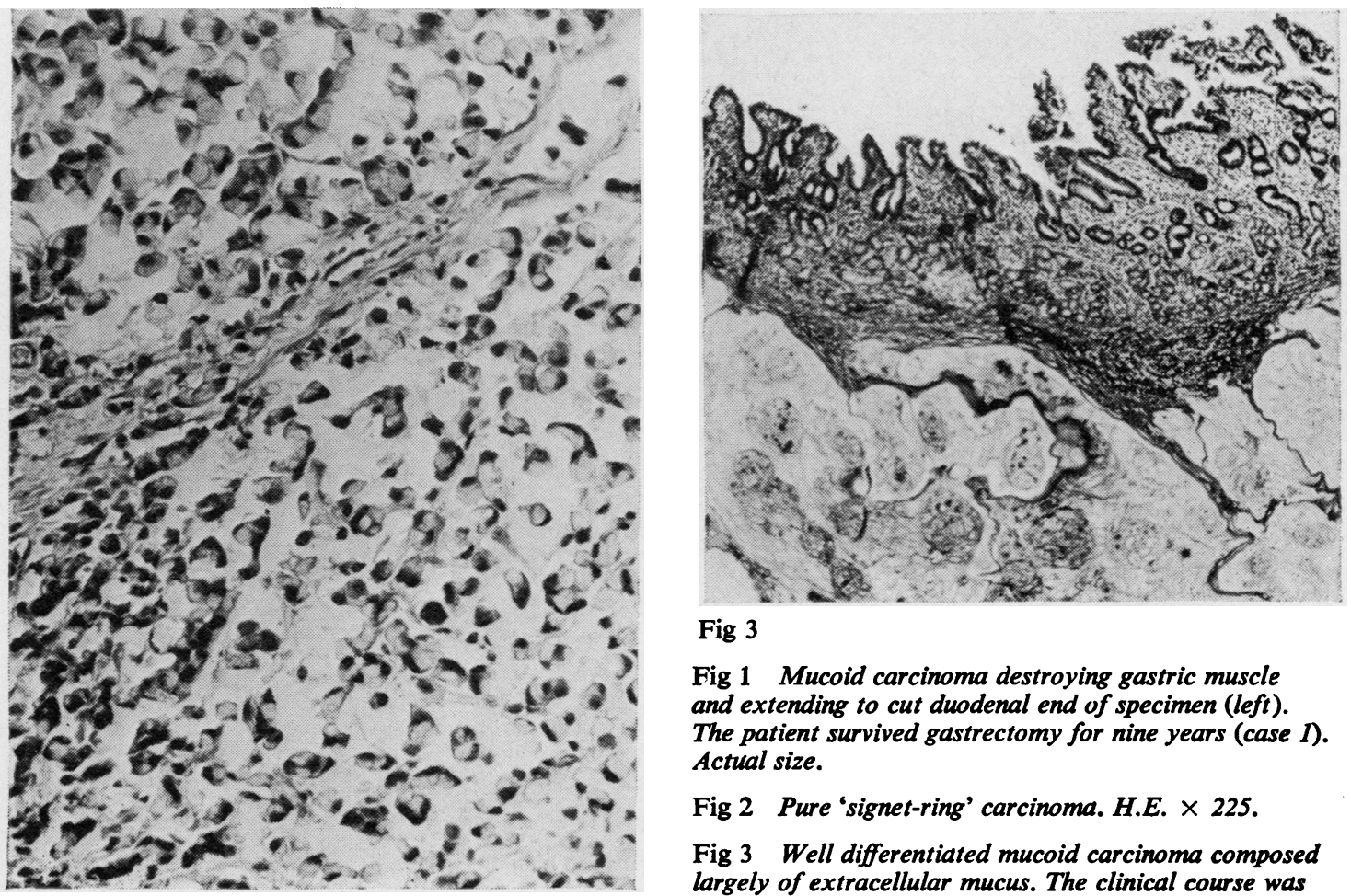

Fig 3

Fig 1 Mucoid carcinoma destroying gastric muscle and extending to cut duodenal end of specimen (left). The patient survived gastrectomy for nine years (case 1). Actual size.

Fig 2 Pure 'signet-ring' carcinoma. H.E. $\times 225$.

Fig 3 Well differentiated mucoid carcinoma composed largely of extracellular mucus. The clinical course was indolent (case 4). HE $\times 30$. 


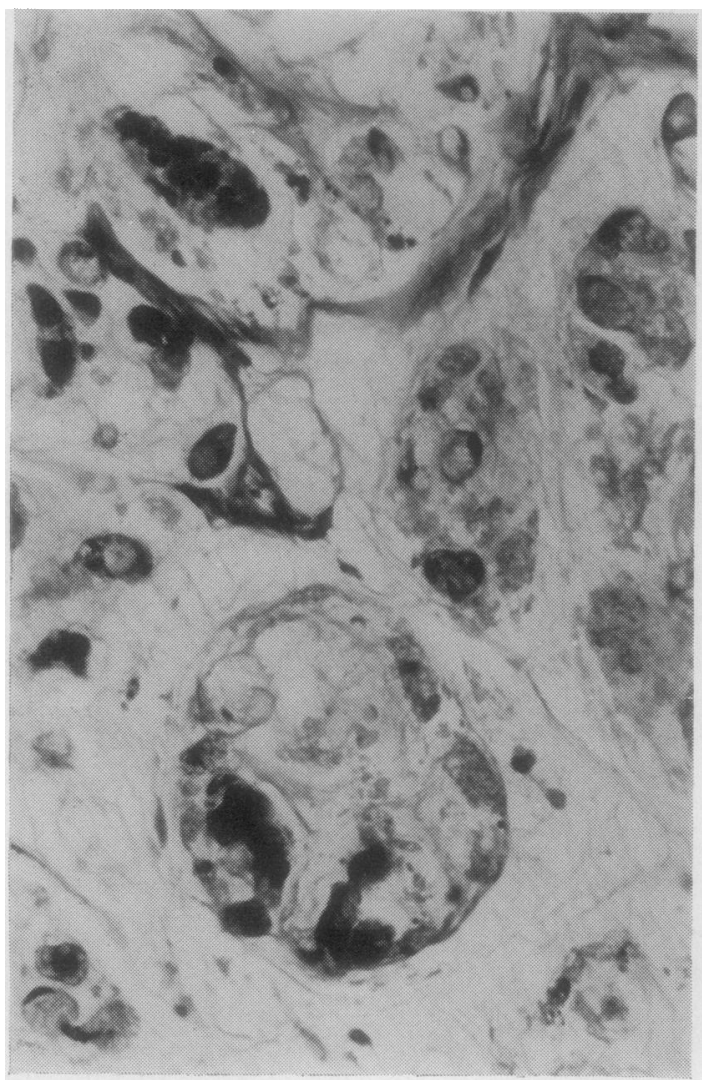

Fig 4 High-power view of tumour seen in fig 3, with tumour cells floating in mucus showing some of the cytological appearances described in the text. $H E \times 500$.

types. A few tumours in this group conform in large part to the pattern of (2) (well differentiated mucoid carcinoma) but include a focus, either in the primary or in a lymph node metastasis, which is more cellular and contains little or no mucus (fig 7).

The stromal reaction was also noted (Inokuchi, Inotsuka, Furusawa, Soejima, and Ikeda, 1967). The extent and spread of each tumour at the time of operation was taken into account and correlated with the survival time of the patient. In calculating mean survival times patients dying within three months of operation were excluded, as in most cases early death is a result of surgical complications rather than the disease (Hawley, Westerholm, and Morson, 1970).

\section{Results}

Of 574 gastric carcinomas reviewed, $50(8.7 \%)$ were

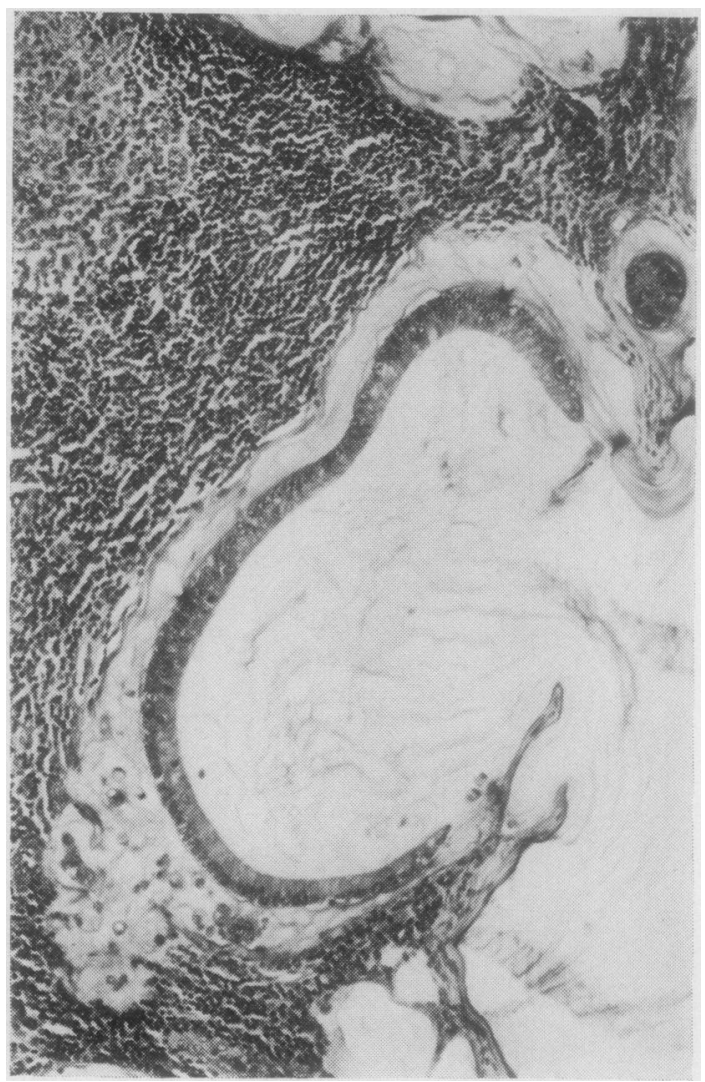

Fig 5 Lymph-node metastasis from tumour shown in figs 3 and 4, showing abundant extracellular mucin, and an incomplete acinus lined by highly differentiated tumour cells. $H E \times 125$.

classified as mucoid. Forty-one of these were of mixed pattern, six well differentiated and only three of pure signet-ring type. The age at operation and sex of the patient are shown in table $I$.

Treatment in $\mathbf{4 9}$ of the $\mathbf{5 0}$ cases was by partial or total gastrectomy; one of the signet-ring tumours was found to be inoperable and was merely biopsied.

\begin{tabular}{|c|c|c|c|c|}
\hline \multirow[t]{2}{*}{ Type of Tumour } & \multirow{2}{*}{$\begin{array}{l}\text { Age at } \\
\text { Operation }\end{array}$} & \multicolumn{2}{|l|}{ Sex } & \multirow{2}{*}{$\begin{array}{l}\text { No. of } \\
\text { Cases }\end{array}$} \\
\hline & & $M$ & $\boldsymbol{F}$ & \\
\hline Signet ring & $\begin{array}{l}51-80 \\
\text { (mean 65.9) }\end{array}$ & 3 & $\mathbf{0}$ & 3 \\
\hline Mixed & $\begin{array}{l}37-83 \\
\text { (mean 62.8) }\end{array}$ & 24 & 17 & 41 \\
\hline $\begin{array}{l}\text { Well differentiated } \\
\text { mucoid }\end{array}$ & $\begin{array}{l}45-76 \\
\text { (mean 58) }\end{array}$ & 6 & 0 & 6 \\
\hline
\end{tabular}

Table I Age and sex distribution of 50 cases of mucoid carcinoma 


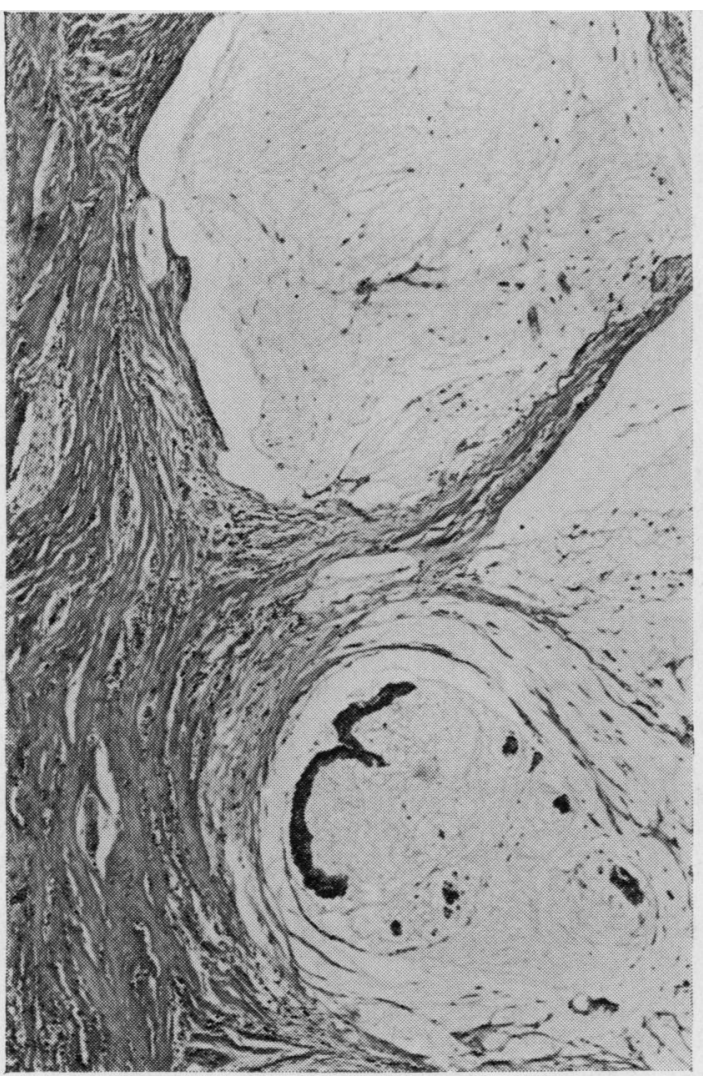

Fig 6

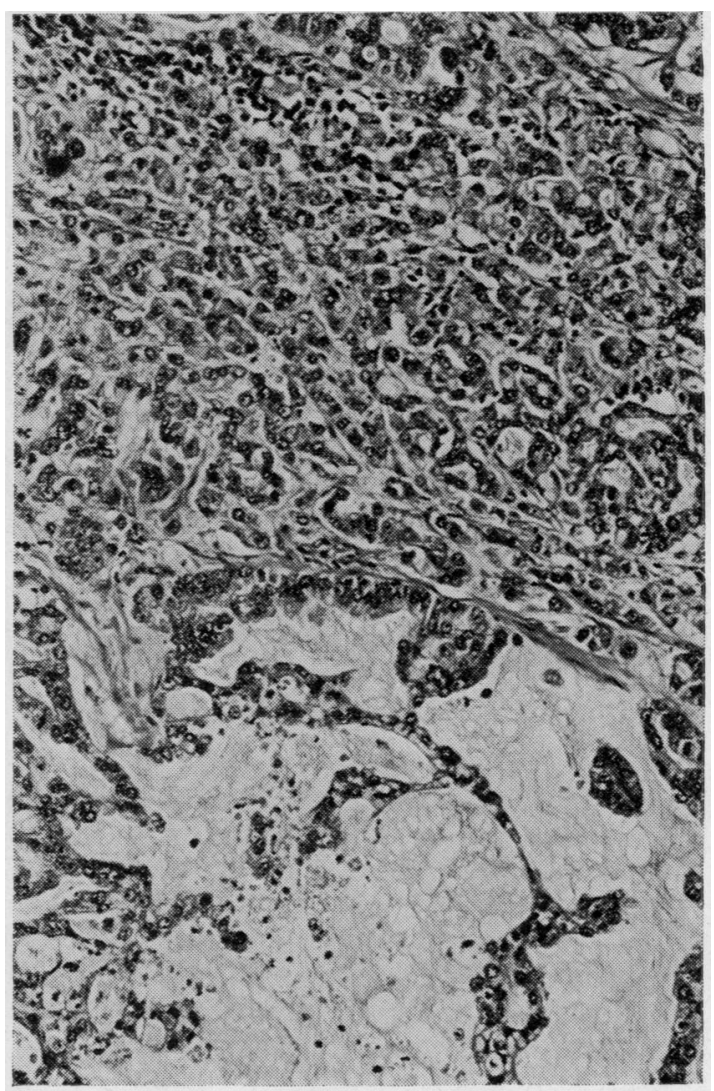

Fig 7

Fig 6 Mucoid carcinoma of indolent type showing masses of extracellular mucin indenting gastric muscle. Similar tumour tissue extended to cut end of specimen (case 3). $H E \times 30$.

Fig 7 Mucoid carcinoma of 'mixed' type, with much extracellular mucus in some areas but showing transition to a more cellular growth pattern. $H E \times 125$.

The largest group of patients, those with mucoid carcinoma of mixed pattern, had a mean survival of 18 months, and even excluding those cases with distant metastases at the time of operation this period could be extended to 21 months only. The three cases of signet-ring pattern had a mean survival of five months.
These figures are in contrast with the six cases of well differentiated mucoid carcinoma where the mean survival was nine years, even including those with lymph-node involvement (see table II). The length of the preoperative case history in these cases did not differ significantly from that of other groups, and varied from four months to several years. The stromal

\begin{tabular}{|c|c|c|c|c|c|}
\hline \multirow[t]{2}{*}{ Case } & \multirow[t]{2}{*}{ Age at Operation } & \multicolumn{2}{|l|}{ Extent of Spread } & \multirow{2}{*}{$\begin{array}{l}\text { Survival after Operation } \\
\text { (years) }\end{array}$} & \multirow[t]{2}{*}{ Cause of Death } \\
\hline & & $\begin{array}{l}\text { Through Stomach } \\
\text { Wall }\end{array}$ & $\begin{array}{l}\text { Lymph Node } \\
\text { Involvement }\end{array}$ & & \\
\hline 1 & 49 & + & - & 9 & $\begin{array}{l}\text { Local recurrence, postoperative } \\
\text { septicaemia }\end{array}$ \\
\hline 2 & 70 & + & + & 9 & Pneumonia; no clinical recurrence \\
\hline 3 & 76 & + & $\begin{array}{l}\text { Tumour in cut end } \\
\text { of specimen }\end{array}$ & 8 & Pneumonia; no tumour found \\
\hline 4 & 45 & + & + & 15 & Local recurrence; carcinomatosis \\
\hline 5 & 50 & - & - & $10+$ Lost to follow up & \\
\hline 6 & 58 & + & - & 3 & Local recurrence; carcinomatosis \\
\hline
\end{tabular}

Table II Follow up of six cases of well differentiated mucoid tumour 
reaction varied from tumour to tumour and from one area to another within the same tumour but was never sufficiently intense to be remarkable.

\section{CASE REPORTS}

\section{Case 1}

Mr A.S. presented, aged 48, with a four months' history of epigastric discomfort. Barium meals disclosed a mass in the pyloric antrum of the stomach (see fig 1) and he underwent a partial gastrectomy on 17 August 1939. Histology showed a well differentiated mucoid carcinoma which had penetrated the muscle coats but did not involve local lymph nodes. He remained well until November 1948 when he was found to have a recurrence of the tumour. This was resected but he died of septicaemia one week later. At necropsy there was tumour in abdominal lymph nodes only.

\section{Case 2}

Mr F.L. presented, aged 70, with eight months' history of diarrhoea and occasional vomiting. He was found to have a gastric carcinoma and a Billroth I gastrectomy was performed on 24 June 1952. The tumour was in the pyloric antrum and proved to be a well differentiated mucoid carcinoma involving local lymph nodes. He remained well and clinically free from recurrence until his death from pneumonia in his eightieth year. A necropsy was not performed.

\section{Case 3}

Mr G.V. presented at the age of 76 with a four-month history of epigastric discomfort. At a Billroth I gastrectomy on 27 October 1973 a mucoid tumour was found in the pyloric antrum (fig 6). Lymph nodes were not examined but the sections showed tumour extending to the cut end of the duodenum. In spite of this incomplete excision he remained well for over eight years, dying at the age of 84 from bronchopneumonia. At necropsy there was no evidence of tumour.

\section{Case 4}

Mr K.H. presented, aged 45, with a long history of epigastric discomfort, having noticed a mass in his abdomen. A carcinoma arising from the lesser curve was excised by partial gastrectomy on 23 July 1957. This mucoid tumour involved local lymph nodes. He remained well until 1972 when he developed a local recurrence (confirmed by biopsy at laparotomy) from which he died 15 years and 7 months after his first operation. There was no necropsy.

\section{Case 5}

Mr F.G. presented with many years' history of dysphagia at the age of 50. On 19 February 1958 a carcinoma of the pylorus was resected by a Billroth I gastrectomy at another hospital. The tumour was confined within the muscle coats and local lymph nodes were not invaded. He continued to be followed and in 1965 the gastrectomy was revised because of a postgastrectomy syndrome. Biopsies were taken and there was no evidence of recurrent tumour. $\mathrm{He}$ was last seen in 1968 ten years after resection of the carcinoma and was well. He has since been lost to follow up.

\section{Case 6}

Mr E.C., aged 58, presented with a four months' history of vomiting and retrosternal pain and more recently the onset of dysphagia. A barium meal showed a mass at the lower end of the oesophagus extending into the stomach. A partial gastrectomy and oesophagectomy was performed on 22 November 1968 but a few months later his symptoms recurred. He was found to have a stricture at the oesophago-gastric anastomosis and this was dilated on several occasions but no biopsies were taken. $\mathrm{He}$ remained reasonably well until three years later when he began to lose weight and his condition slowly deteriorated until he died from carcinomatosis three years and six months after resection. There was no necropsy.

\section{Discussion}

It is widely reported that mucoid carcinoma of the stomach has a poor prognosis (Hoerr, Hazard, and Bailey, 1966; Morson and Dawson, 1972) and that the microscopic appearances are of little value in assisting prognosis (Brookes, Waterhouse, and Powell, 1965; Morson and Dawson, 1972). In this series, however, we have defined a small but easily recognizable group of well differentiated mucoid carcinomas which pursue an indolent course. Willis (1967) records a case of a 'bulky gelatinous adenocarcinoma' of the pylorus in a man aged 65 , who lived for seven and a half years after a laparotomy at which the tumour was considered inoperable, but he does not specifically link the microscopic appearances with the long survival.

It is important to note that these well differentiated mucoid tumours constitute only $1 \%$ of resected carcinomas and $12 \%$ of mucoid carcinomas. The pathologist must be careful not to include tumours with a mixed histological pattern, for in our series we encountered three cases in which most of the tumour was of well differentiated mucoid pattern but in which there was a small area, either in the primary or in one of the lymph nodes, which was more cellular, contained less mucus, and showed a 
more diffuse type of infiltration (fig 7). In practice only a few histological tissue blocks are necessary to reveal this type of mixed pattern. In this series the maximum number of blocks taken was six. However, without a prospective study it is impossible to make specific recommendations on the point, and we can only say that with our material it was remarkably easy to recognize the indolent, well differentiated mucoid carcinoma.

We wish to thank the surgeons of the Westminster and Gordon Hospitals for permission to study these cases. We are grateful to the Department of Medical Photography for help in preparing figure 1 .

\section{References}

Brookes, V. S., Waterhouse, J. A. H., and Powell, D. J. (1965).
Carcinoma of the stomach: a 10-year survey of results and of factors affecting prognosis. Brit. med. J., 1, 1577-1583.

Fisher, E. R., and Hoerr, S. O. (1955). The practical value of histopathological classification of gastric carcinoma: an appraisal based on 100 consecutive cases. Cancer (Philad.), 8, 389-395.

Hawley, P. R., Westerholm, P., and Morson, B. C. (1970). Pathology and prognosis of carcinoma of the stomach. Brit. J. Surg., 57, 877-883.

Hoerr, S. O., Hazard, J. B., and Bailey, D. (1966). Prognosis in carcinoma of the stomach in relation to the microscopic type. Surg. Gynec. Obstet., 122, 485-494.

Inokuchi, K., Inutsuka, S., Furusawa, M., Soejima, K., and Ikeda, T. (1967). Stromal reaction around tumor and metastasis and prognosis after curative gastrectomy for carcinoma of the stomach. Cancer (Philad.), 20, 1924-1929.

Monafo, W. W., Jr., Krause, G. L., Jr., and Medina, J. G. (1962). Carcinoma of the stomach. Morphological characteristics affecting survival. Arch. Surg., 85, 754-763.

Morson, B. C., and Dawson, I. M. P. (1972). Gastrointestinal Pathology. Blackwell, Oxford.

Stout, A. P. (1953). Atlas of Tumour Pathology, Sect. VI, Fasc. 21, Tumours of Stomach, pp. 65-67. Armed Forces Institute of Pathology, Washington D.C.

Willis, R. A. (1967). Pathology of Tumours. 4th ed., p. 396. Butterworth, London. 